\title{
İstismarcı Yönetici Algısının Kişisel Başarı Hissinde Azalma Üzerine Etkisinde Duygusal Tükenmenin Aracı Rolü
}

DOI: $10.26466 /$ opus.584746

$*$

\section{$\underline{\text { Ali Acaray* }}$}

* Dr. Öğr. Üyesi, Recep Tayyip Erdoğan Üniversitesi, Fındıklı / Rize / Türkiye

E-Posta: aliacaray@hotmail.com

ORCID: $\underline{0000-0002-1002-9937}$

Öz

İstismarcı yönetici davranışı, yöneticilerin çalışanlarına yönelik fiziksel saldırıları haricinde sözel ve sözel olmayan düşmanlık davranışlarını içeren bir davranıştır. Örgütlerdeki yıkıcı davranış örneklerinden biri olarak da çalışanların tutum ve davranışları üzerinde etkiler ortaya koyabilmektedir. Kişisel başarı hissinde azalma da, çalı̧̧anın kendi yetersizliğine ve başarısızlığına dair bir değerlendirmesini içermekte olup istismarcı yönetici davranışları ile daha da artabilecektir. Araştırmanın diğer bir değişkeni duygusal tükenme, çalışanların icra ettikleri görevin ortaya çıkardığı stres neticesinde duygusal kaynaklarım büyük miktarda kaybetmiş hissetmesidir. Bu çalışmanın temel amacl, istismarcı yönetici davranışının kişisel başarı hissinde azalma üzerine etkisinde duygusal tükenmenin aracı rolünü araştırmaktır. Araştırmanın verileri anket tekniği ile kamu sektörü okullarında görev yapan 169 öğretmenden elde edilmiştir. Araştırmanın verilerine kolayda örnekleme yöntemiyle ulaşılmıştır. Araştırma sonuçları; istismarcı yönetici algısının kişisel başarı hissinde azalma ve duygusal tükenme üzerinde pozitif etkiye sahip olduğunu; duygusal tükenmenin kişisel başarı hissinde azalma üzerinde pozitif etkiye sahip olduğunu ve duygusal tükenmenin de istismarcı yönetici algısının kişisel başar hissinde azalma üzerine etkisinde aracı rolü üstlendiğini ortaya çıkarmıştır.

Anahtar Kelimeler: $\quad$ Istismarcı yönetici, Kişisel başarı hissi, Duygusal tükenme 


\title{
The Mediator Role of Emotional Exhaustion on the Relationship between Abusive Supervision and Personal Accomplishment
}

\begin{abstract}
Abusive executive behavior is a behavior that includes verbal and non-verbal hostility behaviors, except for physical attacks by managers. As one of the examples of destructive behavior in organizations, it may affect employees' attitude and behaviors. The reduction in the sense of personal accomplishment includes an assessment of the employee's own inadequacy and failure, and may be further enhanced by abusive executive behavior. Emotional exhaustion, which is another variable of the study, is that employees feel a great deal of loss of their emotional resources based on the stress of the task they perform. The main purpose of this study is to explore the mediating role of emotional exhaustion on the effect of abusive supervision on the decrease of personal sense of accomplishment. The data of the study were obtained from 169 teachers working in public sector schools through survey technique. The data of the study were obtained by the convenience sampling method. The results of the research revealed that abusive supervision had a positive effect on the decrease of personal sense of accomplishment and emotional exhaustion; emotional exhaustion had a positive effect on the decrease of personal sense of accomplishment; emotional exhaustion had a mediating role on the effect of abusive supervision on the decrease of personal sense of accomplishment.
\end{abstract}

Keywords: Abusive supervision, Personal accomplishment, Emotional exhaustion 


\section{Giriş}

Örgütlerde yönetim ve astlar arasındaki ilişki ve etkileşimin kalitesi, çalışma koşullarında taraflar adına çok sayıda istenen ve istenmeyen sonuçları beraberinde getirebilmekte ve bu sonuçlar ise örgütlerin amaçlarına ulaşabilmesinde önemli bir ölçüt olarak ortaya çıkmaktadır (Üçok ve Turgut, 2014). Dolayısıyla karşılaşılan örgütsel problemlerin doğru tanımlanmasında ve analiz edilmesinde temelde çalışan ve yöneticisi arasındaki ilişki ve etkileşimin doğru biçimde kavranmasına ihtiyaç vardır (Bolat vd., 2017). Bu kapsamda da liderlik yazınındaki odak nokta artık etkili liderlik davranışlarından liderliğin hem olumlu hem de olumsuz yönlerine doğru kaymaktadır (Wu, 2008). Tierney ve Tepper (2007, s.171) çalışmasında, "yapılan liderlik araştırmalarının üstünlüğünün liderliğin daha yapıcı taraflarına odaklanmış olmasına rağmen, liderlik pozisyonlarındakilerin bazen yıkıcı olma kapasite ve motivasyonuna sahip oldukları olgusuyla örgütlerde artan bir şekilde karşı karşıya kalındığını" ifade etmiştir. Kelloway ve arkadaşları (2006) da işyeri liderliği üzerine yapılan çalışmaların çoğunun olumlu ve yapıcı liderlik biçimlerine odaklanmaları nedeniyle liderliğin karanlık ve yıkıcı tarafının görmezden gelindiğini ifade etmişlerdir. Bu düşüncelerle paralel olarak da liderliğin karanlık taraflarına yönelik toksik liderlik (Goldman, 2011), kötü liderlik (Kellerman, 2004), küçük zorbalık (Ashforth, 1994) gibi kavramların inceleme yapıldığı çalışmalar, yıkıcı liderliğin büyüyen ve dikkate değer bir alan olduğunu da ortaya koymaktadır. Etkili olmayan liderlik çalışmalarının incelediği konulardan biri de yöneticilerin istismarcı davranışı olarak ele alınmaktadır (Tepper, 2000; Tepper, 2007). Ayrıca söz konusu istismarcı yönetimin içeriğindeki olumsuz davranışların sergilenmesinin devamlı bir yükseliş içerisinde olduğu da belirtilmektedir (Pradhan ve Jena, 2017). Bu bağlamda istismarc1 yönetimin sonuçlarına odaklanmayı artırmak gerekmektedir.

İstismarcı yönetici, "astların yöneticisinin fiziksel şiddet haricinde sözlü ve sözel olmayan düşmanca ve işlevsiz davranışlarına uzun bir süreden beri maruz kalmaları halinde oluşturduğu kişisel değerlendirmesi” biçiminde ifade edilmektedir (Tepper, 2000, s.178). Tanımda ön plana ç1kan özellikler; istismarcı yönetici davranışlarının her bir çalışana göre öznellik içermesi, istismar halinin devamlılık kazanması, fiziksel şiddeti 
kapsamaması ve istismarcı davranışta yöneticinin niyetine değil, davranışın kendisine atıf yapılmasıdır (Harris vd., 2007). Çalışanların gözünü korkutmak, onlara maksatlı şekilde risk içeren ya da güç bir görev vermek, onların isteklerine ya da problemlerine ses vermemek, terfilerini daraltmak, onları yapmadıkları şeyler için suçlamak ve onlarla alay etmek istismarcı yönetici davranışları arasında sayılabilir (Tepper, 2000; Tepper, 2007). Dolayısıyla söz konusu eylemler, ilişkilerde karşı tarafın uyumunu sağlamada kişilerarası kötü davranışların önemli bir yönünü açıklar (Wang vd., 2012).

İstismarcı yönetim örgütlerde düşük tabanlı bir olguya sahip olmasına rağmen çalışanların tutum ve davranışları üzerinde arzu edilmeyen sonuçlara sahiptir (Tepper, 2000). Çalışanların iş tatmini ve örgütsel bağlılığ1 (Tepper vd., 2004; Duffy vd., 2002; Tepper, 2000), öz yeterliliği (Duffy vd., 2002), prosedürel adalet algılaması ve örgütsel vatandaşlık davranışı (Tepper vd., 2004; Zellars vd., 2002), bağlamsal performansı (Aryee vd., 2008) ve özgüveninde azalma (Harvey vd., 2007); işyeri-aile, aile-işyeri çatışmaları (Wu ve Cao, 2015; Tepper, 2000), stresle ilgili problemleri -depresyon gibi- (Duffy vd., 2002; Tepper, 2000), iş gerginliği (Harvey vd., 2007), duygusal tükenmesi (Bolat vd., 2017; Grandey vd., 2007; Harvey vd., 2007; Tepper, 2000), aktif ve pasif üretkenlik karşıtı iş davranışları (Duffy vd., 2002), örgüte ve bireye yönelik sapkın davranışları (Üçok ve Turgut, 2014), negatif duyguları (Zellars vd., 2002), işyeri kaytarma davranışı (Sezici ve Güven, 2017) ve işten ayrılma niyetlerinde artış (Pradhan ve Jena, 2017; Harvey vd., 2007) ortaya çıkarabilmektedir. Dolayısıyla istismarcı yönetim, çalışanlar ve örgütler nezdinde önemli sonuçlara neden olabilme kapasitesine sahip bir yönetim konusudur.

Kişisel başarı hissinde azalma çalışmanın bağımlı değişkenidir. Çalışanın kişisel başarısızlığı ya da düşük kişisel yeterliliği, karşılaştığı problemlerle mücadelesinde kendisini yetersiz, güçsüz ve beceriksiz olarak değerlendirmesidir (Duru vd., 2014; Maslach vd., 2001). Kişilerin kendilerine yönelik olumsuz değerlendirmelerde bulunmaları özellikle başarmaya yönelik (öz yeterlilik) duygularının azalmasını beraberinde getirebilir. Taylor (1991) da kişilerarası olumsuz olayların, bireylerin duyuşsal, bilişsel ve davranışsal tepkiler vermesine yol açabileceğini iddia etmiştir (aktaran: Duffy vd., 2002). İstismarcı yönetim davranışlarının hedefi olmuş 
bir çalışanın bu düşünce mekanizmasında duyuşsal, bilişsel ve davranışsal tepkiler vermesi beklenir. İstismarcı yönetim davranışları özellikle de duyuşsal olarak çalışanların çaresizlik, kontrol eksikliği ve sıkıntı duygularını harekete geçirebilir ve bilişsel olarak ise benliğe dair karmaşık bilişsel sonuçları ortaya çıkarabilir (Duffy vd., 2002). Bu bağlamda, istismarcı yönetim davranışları çalışanların iş yaşamlarını etkileyebilecek kişilerarası bir stres kaynağı olarak değerlendirilebilir. Ayrıca istismarcı yönetimin kişiler arası bir çatışma ve çalışanların duyguları, öz yeterliliği ve özgüvenine kronik bir baskı hali olduğu (Harvey vd., 2007) ve dolayısıyla çalışanlar üzerinde etkisinin büyük olduğu ve bu durumun çalışanlar açısından kritik kaynakların kaybedilmesine yol açabileceği ifade edilmektedir (Pradhan ve Jena, 2017). Dolayısıyla istismarcı yönetim çalışanların kişisel başarısızlık hislerini duygusal tükenme vasıtasıyla artırabilir. Bu çalışmanın da temel amacı, istismarcı yönetici algısının kişisel başarı hissinde azalmaya etkisinde duygusal tükenmenin aracı rolünü araştırmaktır. Yazında istismarcı yönetimin işten ayrılma niyetine (Pradhan ve Jena, 2017), işyeri-aile çatışmasına (Wu ve Cao, 2015), işyeri kaytarma davranışına (Sezici ve Güven, 2017), bağlamsal performansa (Aryee vd., 2008) etkisinde duygusal tükenmenin aracllık rolü üstelenmesine yönelik çeşitli çalışmalar mevcuttur. Ayrıca yazında istismarcı yönetimin duygusal tükenme ve kişisel başarı hissi arasındaki ilişkilere dair çalışmalar mevcut olmakla birlikte, istismarcı yönetimin kişisel başarı hissi azalmasına etkisinde duygusal tükenmenin aracı rolünü öğretmenler örneklemi üzerinde inceleyen bir çalışmaya rastlanmamıştır.

Örneklem, kamu sektörü okullarında halen eğitim ve öğretim faaliyetlerini sürdüren öğretmenlerden seçilmiştir. Öğretmenler hedef kitleyle doğrudan iletişim kuran, girdisi ve çıktısı öğrenciler olan bir sistemin en önemli unsurlarındandır. Yöneticileri ile olan ilişkilerinin niteliği, en başta eğitim ve öğretim faaliyetlerinin niteliğini etkileyebilecek ve bu durum da sistemin işleyişi ve performansı üzerinde kaçınılmaz etkiler ortaya koyabilecektir. Çünkü istismara uğrayan öğretmenlerin stres, gerginlik yaşamaları yüksek ihtimaldir. Söz konusu olumsuz duygular da öğretmenlerin tutum ve davranışlarını olumsuz etkileyebilecektir. Dolayısıyla istismarcı yönetici algısının kişisel başarı hissinde azalma üzerine etkisinde duygusal tükenmenin aracı rolünün öğretmelerden elde edilecek verilerin 
analizi ile incelenmesinin hem yazına hem de profesyonel çalışma yaşamına önemli katkılar sunması beklenmektedir. Başka bir ifade ile böyle bir çalışma yapmak, eğitim kurumlarındaki yöneticilerin istismarcı yönetimleri ve bu algılamanın öğretmenlerin tutum ve davranışlarında olası etkileri ve böylece çözüm yollarının neler olabileceğine katkı sağlayabilecektir. Ayrıca böyle bir çalışma ile özellikle öğretmenler örnekleminde sınırlı sayıdaki istismarcı yönetim ve etkilerine dair çalışmaların kapsamı çeşitlenecek ve genişleyecektir.

\section{Hipotez Geliştirme}

\section{İstismarcı Yönetici Algısının Kişisel Başarı Hissinde Azalmaya Etkisi}

Çalışanın kişisel başarı hissine sahip olması, görevini gerçekleştirirken ihtiyaç duyduğu güce ve başarıya ilişkin hissiyatı yaratır. Bu hissiyatın azalması başarı, moral, üretkenlik, özsaygıda azalma ve yetersiz olma durumu olarak açıklanmaktadır (Demir, 2010). İstismarcı yönetim davranışlarının kişilerarası bir stres kaynağı olarak (Harris vd., 2007) ortaya çıkardığgı olumsuzluklar çalışanların duyuşsal, bilişsel ve davranışsal tepkilerine neden olabilecektir. Kaynakların Korunması Teorisi (Conservation of Resources Theory) bağlamında da işyeri stresi; sahip olunan eldeki kaynaklarını tehdit eden ya da kaynakların gerçekten kaybına yol açan ya da kaynak yatırımlarına rağmen yeni kaynak kazanılmasını başarısız kılan iş koşullarına karşı tepkidir. Söz konusu kaynaklar ise maddi kaynaklar, kişisel özellikler, koşullar, ilişkiler ve enerjidir (Hobfoll, 1989). Dolayısıyla teori, çalışanın stres halinde sahip olduğu kaynakları korumak ya da kayıpları azaltmak için tepkiler ortaya koyacağını ileri sürer. Tepper (2000) da yöneticisinin desteğini kaybeden çalışanın stresli hale gelebileceğini ifade etmiştir. Ayrıca istismarcı yönetici davranışları, sürekliliğinden ötürü çalışanın psikolojik açıdan zorluk çekmesine ve böylelikle de uyum kabiliyeti ve direncinde bir azalma yaşamasına neden olabilecektir (Ülkü ve Bilgin, 1983). Bu bağlamda istismarcı yönetici davranışına maruz kalan çalışanın kendi yeterlilik ve başarısına dair değerlendirmesini azaltacağı beklenmektedir. Başka bir ifadeyle, istismarcı yönetici davranışı kapsamındaki istismar halinin sürekliliği, çalışanın özsaygısı ve öz yeterlili- 
ğinde zayıflık ortaya çıkararak başarı hissinde azalma ortaya çıkarabilecektir. Yazında yapılan çalışmalar da istismarcı yönetici davranışının kişisel başarı hissinde azalma ile pozitif ilişkiye sahip olduğunu ortaya koymaktadır (Sezici ve Yıldız, 2017; Aryee vd., 2008; Harvey vd., 2007; Tepper, 2000). Dolayısıyla teori ve yapılmış çalışmalardan hareketle aşağıdaki hipotez ileri sürülmüştür:

- Hı: İstismarcı yönetici algısı kişisel başarı hissinde azalmayı pozitif ve anlaml bir şekilde etkilemektedir.

\section{İstismarcı Yönetici Algısının Duygusal Tükenmeye Etkisi}

Tükenmişliğin alt bileşenlerinden biri olarak duygusal tükenme, çalışanların görevlerine bağlı yaşadıkları strese dayalı olarak kendilerini duygusal güçler bakımından çok fazla tükenmiş/zayıflamış hissetmesidir (Maslach vd., 2001). Duygusal güçlerin tükenme ya da zayıflamasına bağlı olarak çalışanlar kendilerini stresli hissetmekte ve rahat hissedememektedir (Wu ve Cao, 2015). Dolayısıyla istismarcı yönetici davranışına maruz kalmak, işyeri kaynaklı stres tetikleyicilerinden biri olarak da duygusal tükenme ile ilişkilidir (Harvey vd., 2007; Tepper, 2000). İstismarcı yönetimin duygusal tükenme ile ilişkisi Kaynakların Korunması Teorisi bağlamında (Hobfoll, 1989) istismarcı yönetici davranışları liderlik desteği açısından bir çeşit kaynak yitimi ortaya çıkarabilmektedir (Aryee vd., 2008). Çalışanlar karşı karşıya kaldıkları stres faktörleriyle mücadele edecek yeterli miktarda kaynağa sahip olamadıklarında duygusal tükenmeleri artabilmektedir (Lee ve Ashforth, 1996). İstismarcı yönetici davranışlarının sürekliliğinde çalışanın duygusal kaynaklarında tükenme ortaya çıkabilecektir. Konuya dair yapılan çalışmalar da istismarcı yönetici algısı ile duygusal tükenmenin pozitif ilişki içerisinde olduğunu göstermiştir (Bolat vd., 2017; Grandey vd., 2007; Harvey vd., 2007; Tepper, 2000). Dolayısıyla teori ve yapılmış çalışmalardan hareketle aşağıdaki hipotez ileri sürülmüştür:

- Hz: İstismarcı yönetici algısı duygusal tükenmeyi pozitif ve anlamlı bir şekilde etkilemektedir. 


\section{Duygusal Tükenmenin Kişisel Başan Hissinde Azalmaya Etkisi}

Duygusal açıdan tükenmiş çalışanlar kaynaklarında meydana gelen eksilmeye bağlı olarak görevlerini tam kapasite ile sürdürmelerinde güçlükler yaşayabileceklerdir. Çünkü görevinin ortaya koyduğu stres ve iş yoğunluğu çalışanın kendisini yorulmuş ve tükenmiş hissetmesine neden olabilecektir. Dolayısıyla tükenmişlik hali çalışanların duygusuz ve umursamaz bir şekilde karşısındakine davranmasına yol açabilecektir (Demir, 2010). Ayrıca tükenmişlik hissi içerisindeki birinin tekrardan başarı hissine sahip olabilmesi de zordur (Maslach vd., 2001). Çalışan bu koşullarda, kendini yeterlilikten uzak görerek iş tatmini azalmakta ve buna bağlı olarak da kişisel başarı hissinde azalma içerisine girebilmektedir. Duru ve arkadaşlarının (2014) çalışmasında duygusal tükenmişlik ile akademik başarı arasında negatif ilişki olduğu ortaya konulmuştur. Dolayısıyla yapılan açıklama ve çalışmadan hareketle aşağıdaki hipotez ileri sürülmüştür:

- H3: Duygusal tükenme kişisel başarı hissinde azalmayı pozitif ve anlamlı bir şekilde etkilemektedir.

\section{İstismarcı Yönetici Algısının Kişisel Başarı Hissinde Azalmaya Etkisinde Duygusal Tükenmenin Aracı Rolï}

Yöneticilerin istismarcı davranışlarına maruz kalmak; çalışanların niteliksiz ilişki ve etkileşiminin ortaya çıkardığ istenmeyen koşullarla karşılaşması ve bu durumdan sıkıntı, stres duymaları anlamına gelmektedir. Bu durum çalışanlar açısından düşük enerji, yüksek zihinsel yorgunluk/bitkinlik ve stres ortaya çıkararak onları duygusal tükenmeye sevk edebilecektir (Wu ve Cao, 2015). İstismar davranışlarının kaynağıyla savaşmak ve ayrıca örgütün kendisinden beklentilerini yerine getirmek için çabalayan birisi gereğinden fazla kaynağını harcayabilir/tüketebilir ve bu durum çalışanlar açısından düşük kişisel başarı hissi ortaya çıkarabilir. Yazında da istismarcı yönetimin çeşitli değişkenlerle (işten ayrılma niyeti, işyeri kaytarma davranışı, işyeri-aile çatışması, bağlamsal performans) ilişkisinde duygusal tükenmenin aracı rolü ortaya konulmuştur (Pradhan ve Jena, 2017; Sezici ve Güven, 2017; Wu ve Cao, 2015; Aryee vd., 2008). Yapılan açıklamalar kapsamında ileri sürülen hipotez şu şekildedir: 
- $H_{4}$ : Duygusal tükenme istismarcı yönetici algısının kişisel başarı hissinde azalma üzerine etkisinde aracı rolüne sahiptir.

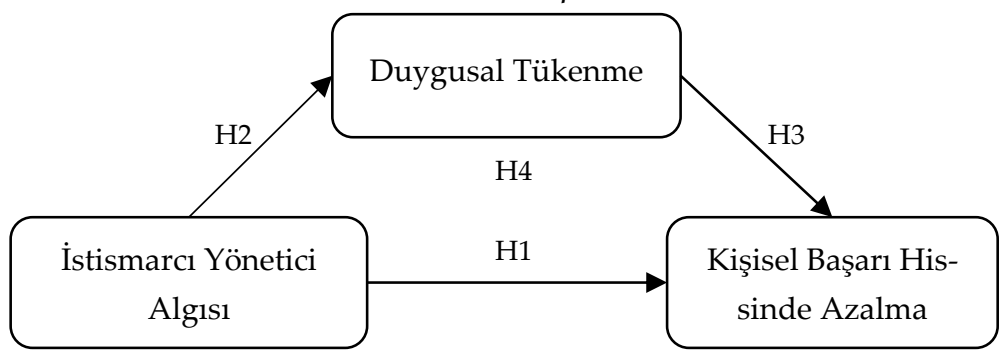

Şekil 1. Araştırmanın Modeli

İstismarcı yönetici algısı, kişisel başarı hissinde azalma ve duygusal tükenme değişkenleri arasındaki araştırma amacı istikametinde geliştirilen hipotezleri içeren araştırma modelinin gösterimi Şekil 1'dedir.

\section{Yöntem}

\section{Örnekleme Süreci ve Örneklemin Demografik Sonuçları}

Araştırmanın evreni, Giresun ve Rize il merkezlerindeki ortaokullarda halen görev yapan öğretmenlerden oluşmaktadır. Örneklem ise ilgili merkezlerdeki okullardan kolayda örnekleme yöntemiyle seçilen 169 öğretmendir. Anket formu internet ortaminda hazırlanan bir link vasitasiyla öğretmenlerin e-postalarına gönderilmiş ve geri dönüş yapanların sayısı 169 olarak ortaya çıkmıştır. 169 öğretmenin demografik sonuçları incelendiğinde; \% 74'ünün kadınlardan, \% 88'inin lisans ve \% 12'sinin yüksek lisans mezunlarından, \% 75'inin evlilerden oluştuğu ve ortalama yaşları 33,40 ve ortalama meslekte çalışma süreleri ise 9,42 yıl olarak ortaya çımiştır.

\section{Araştırmada Kullanılan Ölçekler}

Araştırmaya katılanlara demografik bilgilerinin öğrenilmesi ve istismarc1 yönetici, duygusal tükenme ve kişisel başarı hissinde azalma algılamala- 
rının ölçülmesine yönelik dört farklı grupta sorular sorulmuştur. Demografik bilgilerle ilgili altı adet soru sorulmuştur. Araştırmanın değişkenleri ise " $1=$ Kesinlikle katılmıyorum ve $5=$ Kesinlikle katılıyorum" şeklindeki 5’li likert tipindeki ölçeklerle ölçülmüştür.

Öğretmenlerin istismarcı yönetici algılamaları, Tepper'ın (2000) geliştirdiği ve Ülbeği ve arkadaşlarının (2014) Türkçe’ye uyarladığı 15 ifadeli ve tek boyutlu ölçek ile ölçülmüştür. Ölçekteki sorulardan birisi "Yöneticim/amirim diğer kişilere benim hakkımda olumsuz şeyler söyler" şeklindedir. Ülbeği ve arkadaşlarının (2014) çalışmasında ölçeğin güvenilirliği 0,97 olarak hesaplanmıştır.

Öğretmenlerin duygusal tükenme ve kişisel başarı hissinde azalma algılamaları ise Maslach ve Jackson'ın (1981) geliştirdiği tükenmişlik envanterinden Ergin'in (1992) Türkçe'ye uyarladığ 22 soruluk ölçeğin 17 sorusu ile ölçülmüştür. Kalan 5 soru ise duyarsızlaşma boyutuna aittir. Duygusal tükenme alt boyutuna ilişkin sorulardan birisi "İşimde çok fazla çalıştığımı hissediyorum" şeklindedir. Kişisel başarı hissinde azalma alt boyutuna ilişkin sorulardan birisi ise "İşim gereği karşılaştığım insanlarla aramda rahat bir hava yaratırım" şeklindedir. Bu boyuta ilişkin ifadeler ters puanlanmıştır. Ardıç ve Polatcı'nın (2008) çalışmasında duygusal tükenmenin güvenilirliği 0,81 ve kişisel başarı hissi değişkeninin güvenilirliği ise 0,76 olarak hesaplanmıştır.

\section{Verilerin Analizi}

Araştırma ölçeklerinin geçerlilik ve güvenilirlikleri SPSS 23.0 ve SmartPLS 3.0 programlarıyla tespit edilmiştir. Araştırma modelinin geçerlilik ve güvenilirlik ölçümü ve modelin parametrelerinin hesaplanması yapısal eşitlik modeli kapsamında kısmi en küçük kareler (PLS-Partial Least Squares) ile yapılmıştır. PLS, yapısal eşitlik modeli yapılabilmesinde AMOS ve LISREL gibi diğer kovaryans tabanlı klasik yaklaşımlardan farklı olarak, bileşen tabanlı yeni bir yaklaşımdır. İlgili yazında da PLS, küçük örneklemlerle analiz yapabilmede ve karmaşık modelleri tahminleyebilmede uygun bir yöntem olarak yer almaktadır. Ayrıca bileşen tabanlı YEM yaklaşımın (PLS), kovaryans tabanlı YEM yaklaşımlarından bir farkı da, normal dağılım varsayımını zorunlu kılmamasıdır (Chin, 2001). 


\section{Bulgular}

\section{Ölçeklerin Geçerlilik ve Güvenilirlikler Bulguları}

Ölçeklerin yapısal geçerliliğinde keşfedici (EFA) ve doğrulayıcı faktör analizleri (CFA), güvenilirlikleri ise Cronbach's alfa ( $\alpha \geq .70)$, bileşik güvenilirlik ( $C R \geq .70)$ ve hesaplanan ortalama varyans (AVE $\geq .50)$ ile analizleri yapılmıştır (Hair vd., 2016).

Ölçeklerin KMO değerleri; istismarcı yönetici 0,926 (Bartlett testinin $p$ değeri 0,000), duygusal tükenme ve kişisel başarı hissinde azalma ise 0,873 (Bartlett testinin p değeri 0,000) hesaplanmıştır. KMO değerleri için kabul edilen alt sınır değer 0,50 (Field, 2000) olup; kullanılan ölçeklerin KMO sonuçlarının 0,50'nin üzerinde olması nedeniyle faktör analizi yapılmıştır. Faktör analizinde çıkarım yöntemi olarak temel bileşen analizi, rotasyon yöntemi olarak ise Varimax kullanılmıştır. Ölçeklerin hesaplanan EFA değerleri Tablo 1'dedir. Ölçeklerin faktör analizi sonuçlarında özdeğerlere ilişkin bulgulara göre; istismarcı yönetici değişkeninin 10,026, duygusal tükenme değişkeninin 5,294 ve kişisel başarı hissinde azalma değişkeninin ise 3,018 olup birin üzerinde değerler olarak ortaya çıkmıştır. İstismarc1 yönetici algısındaki on beş ifade toplam varyansın \% 66,84'ünü; duygusal tükenmedeki sekiz ifade toplam varyansın \% 30,13'ünü ve kişisel başarı hissinde azalmadaki yedi ifade ise toplam varyansın $\% 24,46$ 'sını açıklamaktadır.

Ölçeklerin tespit edilen faktöryel yapıları doğrulayıcı faktör analizi ile (CFA) sinanmıştır. Faktör analizinde duygusal tükenme faktöründe bir adet sorunun (faktör yükü; 0,023) ve kişisel başarı hissinde azalma faktöründe ise bir adet sorunun (faktör yükü; 0,386 ) faktör yükünün düşük olduğu görülmüş; bu iki soru ilgili faktörlerin içeriklerinde bir sorun teşkil etmeyeceği değerlendirilerek analiz dışında bırakılmıştır. Araştırma modelinde yer alan değişkenlerin ortaya çıkan faktör yükleri, AVE, CR ve Alfa değerlerine dair sonuçlar Tablo 1'de görülmektedir. Bununla birlikte ayrışma geçerliliğinin tespiti gerekmekte olup; buradaki hesaplamalarda her bir değişkenin AVE değerinin karekökünün değişkenler arasındaki korelasyon değerlerinden büyük olması gerekir (Fornell ve Larcker, 1981). Tablo 2'de parantez içerisindeki değerler ayrışma geçerliğine ilişkin analiz 
sonuçları olup, burada da bir sorunun olmadığı görülmektedir. Dolayısıyla yapılan analiz sonuçları, değişkenlerin tek boyutlu olduğunu ve gerekli geçerlilik ve güvenirlik şartlarını karşıladığını ortaya koymaktadır.

Tablo 1. Faktör ve Güvenirlik Analizi Sonuçları

\begin{tabular}{|c|c|c|c|c|c|c|}
\hline \multirow{2}{*}{ Ölçekler } & \multirow{2}{*}{ Maddeler } & \multicolumn{2}{|c|}{ Faktör Yükleri } & \multirow{2}{*}{ AVE } & \multirow{2}{*}{ CR } & \multirow{2}{*}{ Alfa } \\
\hline & & EFA & CFA & & & \\
\hline \multirow{15}{*}{$\begin{array}{l}\text { İstismarcı } \\
\text { Yönetici } \\
\text { Algısı (İYA) }\end{array}$} & IYYA 1 & 0,843 & 0,761 & \multirow{15}{*}{0,598} & \multirow{15}{*}{0,917} & \multirow{15}{*}{0,912} \\
\hline & İYA 2 & 0,776 & 0,755 & & & \\
\hline & İYA 3 & 0,574 & 0,721 & & & \\
\hline & İYA 4 & 0,692 & 0,819 & & & \\
\hline & İYA 5 & 0,756 & 0,779 & & & \\
\hline & İYA 6 & 0,706 & 0,724 & & & \\
\hline & İYA 7 & 0,731 & 0,718 & & & \\
\hline & İYA 8 & 0,694 & 0,806 & & & \\
\hline & İYA 9 & 0,822 & 0,729 & & & \\
\hline & İYA 10 & 0,640 & 0,797 & & & \\
\hline & IYYA 11 & 0,673 & 0,823 & & & \\
\hline & İYA 12 & 0,793 & 0,801 & & & \\
\hline & IYYA 13 & 0,592 & 0,766 & & & \\
\hline & IYYA 14 & 0,560 & 0,784 & & & \\
\hline & İYA 15 & 0,795 & 0,804 & & & \\
\hline \multirow{9}{*}{$\begin{array}{l}\text { Duygusal } \\
\text { Tükenme (DT) }\end{array}$} & DT 1 & 0,761 & 0,771 & \multirow{9}{*}{0,559} & \multirow{9}{*}{0,909} & \multirow{9}{*}{0,884} \\
\hline & DT 2 & 0,805 & 0,797 & & & \\
\hline & DT 3 & 0,794 & 0,800 & & & \\
\hline & DT 4 & 0,781 & 0,789 & & & \\
\hline & DT 5 & 0,886 & 0,902 & & & \\
\hline & DT 6 & 0,711 & 0,670 & & & \\
\hline & DT 7 & $*$ & $* *$ & & & \\
\hline & DT 8 & 0,550 & 0,598 & & & \\
\hline & DT 9 & 0,559 & 0,602 & & & \\
\hline \multirow{8}{*}{$\begin{array}{l}\text { Kişisel } \\
\text { Başarı } \\
\text { Hissinde Azalma } \\
\text { (KBHA) }\end{array}$} & KBHA 1 & 0,785 & 0,674 & \multirow{8}{*}{0,509} & \multirow{8}{*}{0,877} & \multirow{8}{*}{0,839} \\
\hline & KBHA 2 & 0,834 & 0,804 & & & \\
\hline & KBHA 3 & 0,822 & 0,832 & & & \\
\hline & KBHA 4 & 0,706 & 0,769 & & & \\
\hline & KBHA 5 & 0,648 & 0,647 & & & \\
\hline & KBHA 6 & 0,575 & 0,674 & & & \\
\hline & KBHA 7 & 0,541 & 0,546 & & & \\
\hline & KBHA 8 & $*$ & $* *$ & & & \\
\hline
\end{tabular}

*: Farklı bir faktör altında kaldığı için analize katılmamıştır.

**: Faktör yükleri düşük olduğu için analize katılmamıştır. 
Değişkenler arasındaki ilişkileri ortaya koymak için korelasyon analizi uygulanmıştır. Tablo 2'deki analiz sonuçları, istismarcı yönetici algısının kişisel başarı hissinde azalma $(r=0,193, p<0,05)$, istismarcı yönetici algısının duygusal tükenme $(r=0,461, p<0,01)$ ve duygusal tükenmenin ise kişisel başarı hissinde azalma $(\mathrm{r}=0,340, \mathrm{p}<0,01)$ ile arasındaki ilişkilerin pozitif olduğunu ortaya koymaktadır.

Tablo 2. Korelasyonlar ve Ayrışma Geçerlilik Değerleri

\begin{tabular}{llll}
\hline Değişkenler & $\mathbf{( 1 )}$ & $\mathbf{( 2 )}$ & $\mathbf{( 3 )}$ \\
\hline İstismarcı Yönetici Algısı (1) & $(0,773)$ & & \\
Kişisel Başarı Hissinde Azalma (2) & $0,193^{*}$ & $(0,713)$ & \\
Duygusal Tükenme (3) & $0,461^{* *}$ & $0,340^{* *}$ & $(0,748)$ \\
\hline Ortalama & 1,61 & 1,86 & 2,23 \\
Standart Sapma & 0,7110 & 0,4857 & 0,8795 \\
\hline
\end{tabular}

$N: 169{ }^{*} p<0,05,{ }^{* *} p<0,01$

\section{Hipotez Testleri}

Araştırmada ileri sürülen modelin gücünün ve değişkenler arası ilişkilerin ortaya konulabilmesinde en küçük kareler (PLS) yol analizi; beklenen ilişkilerin istatistiksel yönden anlamlılıklarının belirlenmesinde SmartPLS programında önyükleme yapılarak yeniden-örnekleme yöntemi kullanılmıştır (Chin vd., 2003). Yeniden-örnekleme süreci orijinal veriler yerine tesadüfi olarak seçilmiş 5000 alt-örneklem oluşturmayı içermektedir (Hair vd., 2013). Tesadüfi olarak seçilen her bir alt-örneklemin yol katsayıları ( $\beta$ ) ve t-istatistik değerleri hesaplanmıştır (Tablo 3).

Tablo 3. Hipotez Test Sonuçları

\begin{tabular}{|c|c|c|c|c|c|c|c|}
\hline & Yol & & B & $t$ & $p$ & Hipotez & Sonuç \\
\hline $\begin{array}{l}\text { İstismarc1 } \\
\text { Yönetici Alg1s1 }\end{array}$ & $\rightarrow$ & $\begin{array}{l}\text { Kişisel Başarı } \\
\text { Hissinde } \\
\text { Azalma }\end{array}$ & 0,21 & 2,759 & 0,006 & $\mathrm{H} 1$ & $\begin{array}{l}\text { Destek- } \\
\text { lendi }\end{array}$ \\
\hline $\begin{array}{l}\text { İstismarc1 } \\
\text { Yönetici Alg1S1 }\end{array}$ & $\rightarrow$ & $\begin{array}{l}\text { Duygusal } \\
\text { Tükenme }\end{array}$ & 0,46 & 7,381 & 0,000 & $\mathrm{H} 2$ & $\begin{array}{l}\text { Destek- } \\
\text { lendi }\end{array}$ \\
\hline $\begin{array}{l}\text { Duygusal } \\
\text { Tükenme }\end{array}$ & $\rightarrow$ & $\begin{array}{l}\text { Kişisel Başarı } \\
\text { Hissinde } \\
\text { Azalma }\end{array}$ & 0,32 & 4,025 & 0,000 & $\mathrm{H} 3$ & $\begin{array}{l}\text { Destek- } \\
\text { lendi }\end{array}$ \\
\hline
\end{tabular}

${ }^{*} p<0,05 .{ }^{* *} p<0,01$ 
İstismarcı yönetici algısının kişisel başarı hissinde azalma $(\beta=0,21$, $\mathrm{p}<0,01)$ üzerine etkisi pozitif olup istatistiksel açıdan anlamlıdır. Dolayısıyla H1 hipotezi desteklenmiştir.

İstismarc1 yönetici algısının duygusal tükenme $(\beta=0,46, \mathrm{p}<0,01)$ üzerine etkisi pozitif olup istatistiksel açıdan anlamlıdır. Dolayısıyla H2 hipotezi desteklenmiştir.

Duygusal tükenmenin kişisel başarı hissinde azalma $(\beta=0,32, p<0,01)$ üzerine etkisi pozitif olup istatistiksel açıdan anlamlıdır. Dolayısıyla H3 hipotezi desteklenmiştir.

Geliştirilen yapısal modelde, istismarcı yönetici algısının duygusal tükenme üzerindeki değişimin \% 21'ini $\left(R^{2}=0,21\right)$, istismarc1 yönetici alg1s1nın duygusal tükenme ile birlikte ise kişisel başarı hissinde azalma üzerindeki değişimin \% $11^{\prime}$ ini $\left(R^{2}=0,11\right)$ açıklamaktadır.

Duygusal tükenmenin aracılık testi işlemleri SmartPLS programı kullanılarak toplam etki yöntemiyle yapılmıştır. Söz konusu yöntemin arac1lık testinde kullanılmasının Sobel, güç analizi ile Tip I ve II hata testleri (MacKinnon vd., 2004) gibi diğer test metotlarına göre daha iyi tahminlemede bulunduğu belirtilmektedir. Aracılık rolünün incelenmesinde dolaylı etkilerin anlamlı olup olmaması hem aracı değişkenlerin modele katılmaması (C yolu ile gösterilen toplam etki) hem de katılması ( $C^{\prime}$ yolu ile gösterilen direk etki) durumlarında test edilmelidir. Aracilık işleminden önce de bağımsız değişkenin bağımlı değişkeni etkilediği sağlanmalıdır. Baron ve Kenny'nin (1986) üç adımlı prosedürü şöyledir: i) bağımsız değişkenin aracı değişkene bir etkisi olmalı; ii) aracı değişkenin bağımlı değişkene bir etkisi olmalı ve iii) bağımsız değişkenin de bağımlı değişkene bir etkisi olmalıdır. Bağımsız ile aracı değişkenin modele aynı anda katılması halinde bağımlı değişken üzerine etkileri incelendiğinde ise, ya bağımsız değişkenin etkisinde bir azalma (kısmi aracı etkisi) ya da bağımsız değişken etkisinin tamamen ortadan kalkması gerekir (tam aracı etkisi). Ayrıca etki oranlarının $\left(\mathrm{R}^{2}\right)$, ara etkilerle aracı(lar) aracılığıyla açıklanan toplam etkinin miktarının gösterilmesinde hesaplanması gerekir. Özetle açıklanan toplam etki yöntemi; aracılık rolünün ortaya konulabilmesinde kullanılan nicel bir yöntem olarak, tam ve kısmi aracılığı hesaplayabilmektedir (Shrout ve Bolger, 2002). 
Tablo 4'te, istismarcı yönetici algısı ile kişisel başarı hissinde azalma arasında dolaylı ilişkiler görülmektedir.

Tablo 4. Yapisal Modeldeki Dolaylı Etki

\begin{tabular}{llll}
\hline İlişki & & & $\begin{array}{l}\text { Dolaylı Etki } \\
(\beta)\end{array}$ \\
\hline İstismarcı Yönetici Algısı -> & $\begin{array}{l}\text { Duygusal } \\
\text { Tükenme-> }\end{array}$ & $\begin{array}{l}\text { Kissisel Başarı } \\
\text { Hissinde Azalma }\end{array}$ & $0,147^{* *}$ \\
\hline
\end{tabular}

İstismarcı yönetici algısının kişisel başarı hissinde azalmayı etkilemesinde duygusal tükenmenin aracı rolü ile ilgili ulaşılmış sonuçlar Tablo 5 'te sunulmaktadir.

Tablo 5. Duygusal Tükenmenin Aracılık Rolü

\begin{tabular}{lllll}
\hline \multirow{2}{*}{ Duygusal Tükenmenin Aracı Rolü } & $\begin{array}{l}\text { Toplam } \\
\text { Etki C yolu }\end{array}$ & $\begin{array}{l}\text { Toplam } \\
\text { Etki C' yolu }\end{array}$ & \multirow{2}{*}{ Etki Oran } \\
\cline { 3 - 4 } & $(\beta)$ & $(\beta)$ & \\
\hline İstismarc1 Yönetici & Kişisel Başarı & & & \\
Alg1S1 -> & Hissinde Azalma & $0,211^{*}$ & 0,046 & 0,70 \\
\hline
\end{tabular}

İstismarcı yönetici algısının kişisel başarı hissinde azalmayı etkilemesinde duygusal tükenme değişkeni tam aracı rolü üstlenmekte olup; bu tam aracılığın etki oranı 0,70 tespit edilmiştir. Dolayısıyla H4 hipotezi desteklenmiştir.

\section{Sonuç ve Tartışma}

Yazında istismarcı yönetim, liderliğin karanlık ve yıkıcı taraflarını ön plana çıaran yönetim tiplerinden biri olarak çalışan tutum ve davranışları üzerinde etkili olabilmektedir. Örgütlerde düşük tabanlı olarak görülmesine rağmen yazındaki çalışmaların da ortaya koyduğu gibi ciddi sonuçlar ortaya çıkarabilmektedir. Dolayısıyla söz konusu sonuçlar etkili liderlik davranışları yanında etkili olmayan liderlik davranışlarının da önemini ortaya koymaktadır. Bu bağlamda istismarcı yönetici algısının kişisel başarı hissinde azalma üzerine etkisinde duygusal tükenmenin aracı rolünü araştırmak için kamu sektöründeki okullarda görev yapan öğretmenler örnekleminde gerçekleştirilen bu çalışmanın ulaştığı sonuçlar, 
özellikle sistem girdisinin ve çıktısının insan olduğu bir sektör için değerli sonuçlardır.

Araştırmada öğretmenlerin incelenen değişkenlere dair algılamalarına bakıldı̆̆ında; istismarcı yönetici ve kişisel başarı hissinde azalma algısı katılmıyorum seviyesine yakın, duygusal tükenme algılaması ise katılmıyorum ile kararsızım arası seviyede ortaya çıkmıştır.

Ulaşılan temel bulguya göre, istismarcı yönetici algısı kişisel başarı hissindeki azalma seviyesini artırmaktadır. İstismarcı yönetici davranışlarına maruz kalan çalışanlar, bu davranış karşısında çeşitli tepkiler gösterebilmektedir. Ortaya çıkan stresli hal, çalışanların örgütünde sahip olduklarını elde tutup tutamayacaklarına dair endişe durumudur. Ayrıca yöneticinin istismarcı davranışlarda bulunması çalışanın yönetici desteğinin azalması ya da kaybı anlamına da gelebilir. İstismarcı yönetimdeki davranışların devam etmesi çalışanların sahip oldukları psikolojik kaynaklarda (öz yeterlilik, öz sayg1) tükenme oluşturarak amaçlarına ulaşmada yetersizlik duygularını beraberinde getirebilir. Dolayısıyla kişisel başarısızlık hisseden öğretmenlerin eğitim faaliyetlerini başarılı bir şekilde sürdürmeleri ve kaliteli nesiller yetiştirmeleri güçleşebilecektir. Ulaşılan bu sonuç, konuyla ilgili yapılan çeşitli çalışmaların sonuçlarıyla tutarlıdır (Sezici ve Yild1z, 2017; Aryee vd., 2008; Harvey vd., 2007; Tepper, 2000).

Ulaşılan diğer bulguya göre, istismarcı yönetici algısı duygusal tükenmeyi artırmaktadır. Ĕ̆ger çalışan görevinin ortaya çıkardığı stresle mücadele edebilmesinde gerekli duygusal kaynaklardan yoksunsa tükenmeyi yaşayabilecektir. Ayrıca istismarcı yönetim, yönetici desteğinin kaybı anlamına gelebildiği için söz konusu destekten mahrum kalmak çalışanların ortaya çıkabilecek olumsuz davranışlara karşılık verebilmesini zorlaştırabilecektir. Ulaşılan bu sonuç, önceki çalışmaların sonuçlarıyla da uyumludur (Bolat vd., 2017; Grandey vd., 2007; Harvey vd., 2007; Tepper, 2000). Ayrıca duygusal tükenme öğretmenlerin kişisel başarısızlık hislerini artırmaktadır. Zorlukların üstesinden gelebilmede duygusal kaynakların kaybı, çalışanın başarılı olacağına ilişkin inancını olumsuz olarak etkiyebilecektir. Ulaşılan bu sonuç da, Duru ve arkadaşlarının (2014) duygusal tükenmişlik ile akademik başarı arasındaki negatif ilişkiye dair ulaştıkları sonuçla uyumludur.

Aracılık etkisine dair ulaşılan bulguya göre ise, duygusal tükenme istismarcı yönetici algısının kişisel başarı hissinde azalma üzerine etkisinde 
tam aracı rolü üstlenmiştir. İstismarcı yönetici algısının kişisel başarı hissinde azalma üzerinde pozitif etkisi duygusal tükenme üzerinden gerçekleşmektedir. Başka bir deyişle de çalışanın yöneticisinin istismarına bağlı olarak kişisel başarısızlık hissinde azalma yaşaması için duygusal tükenme algısının mevcudiyeti gerekmektedir.

$\mathrm{Bu}$ çalışmanın uygulama açısından ortaya koyduğu önemli sonuçlar söz konusudur. Okullarda yönetim kadrosunda (okul müdürleri) bulunanların öğretmenleriyle alay etme, onları herkesin içinde küçük düşürme ve sessiz kalarak cezalandırma, onlara yalan söyleme ve kaba davranmaları öğretmelerin hem kişisel başarısızlıklarını hem de duygusal tükenmelerini artırmaktadır. Her iki olumsuz sonucun öğretmenlerin eğitim ve öğretim faaliyetleri sürecinde başta öğrenci ile olan ilişki ve etkileşimlerinde, sınıf yönetimlerinde, derslere hazırlanmalarında, sınavlarda karşılaşılacak stresin üstesinden gelebilmelerinde zayıflık ortaya çıkarabileceği yüksek bir ihtimaldir. Dolayısıyla temelde yöneticilerin bu tür davranışlardan kaçınmaları gerekmektedir. Ayrıca duygusal tükenmenin istismarcı yönetici algısı ile kişisel başarı hissinde azalma arasındaki ilişkide tam aracı rolü üstlenmesi, yönetici posizyonundakiler için de önemli konu olarak ortaya çıkmıştır. Yöneticilerin istismarcı yönetici davranışlarından kaçınmaları yanında çalışanların duygusal tükenmelerini azaltacak uygulamaları örgüt içinde artırmaları gerekmektedir.

Bu çalışmanın yalnızca kamu sektöründe tam gün olarak çalışmakta olan öğretmenlerden ankete iştirak edenler üzerinde gerçekleştirilmesi, önemli bir kısıtlamasıdır. Bu konularla ilgili çalışmalar yapacaklara istismarcı yönetici davranışlarının hem rol içi davranışlara (görev performansı) hem de rol ötesi davranışlara (örgütsel vatandaşlık davranışları, bağlamsal performans, bilgi paylaşma gibi) etkisini başka sektör ve örneklemler üzerinde incelemeleri önerilebilir. 


\title{
EXTENDED ABSTRACT
}

\section{The Mediator Role of Emotional Exhaustion on the Relationship between Abusive Supervision and Personal Accomplishment}

\author{
Ali Acaray \\ Recep Tayyip Erdogan University
}

The quality of interaction and relationship between managers and subordinates in organizations bring many positive and negative results for the related parties in the organizational conditions and these results are considered as an important criterion for the organizations to achieve their goals (Ucok and Turgut, 2014). Because of that, it is necessary to properly understand the relationship and interaction between employee and manager in order to correctly identify and analyze organizational problems (Bolat et al., 2017). In this context, the focus on leadership literature is changed from effective leadership behaviors to both positive and negative behaviors of leadership ( $\mathrm{Wu}, 2008)$. In their study, Tierney and Tepper (2007, p.171) stated that although superiority of leadership researches focused on more constructive aspects of leadership, managers in leadership positions have sometimes destructive capacity and motivation. Kelloway et al. (2006) stated that because most of the studies on workplace leadership focus on positive and constructive leadership styles, dark and destructive sides of leadership are ignored. In parallel with this, concepts such as toxic leadership(Goldman, 2011), bad leadership (Kellerman, 2004), petty tyranny (Ashforth, 1994), which address the darker aspects of leadership, were studied. Abusive supervision is considered as one of the non-influential types of leadership (Tepper, 2000; Tepper, 2007). In addition, it is stated that the abusive manager behaviors are constantly rising in practice (Pradhan and Jena, 2017). In this context, it is necessary to focus on the consequences of abusive supervision.

The abusive supervision is expressed as employee' personal evaluation for his/her manager if employee has been exposed to verbal and non-verbal hostile and dysfunctional behaviors for a long time, except for physical 
attack (Tepper, 2000, p.178). Negative attitudes and behaviors such as intimidating the employees, deliberately giving them a risky or difficult task, keeping silent to their questions / problems, restricting their promotion can be counted among abusive manager behaviors (Tepper, 2000; Tepper, 2007). These behaviors are interpersonal bad behaviors to ensure compliance of the other party (Wang et al., 2012).

Although abusive supervision occur a low-based phenomenon in organizations, it has remarkable results on employees' attitudes and behaviors (Tepper, 2000). While there are negative relationships between abusive supervision and job satisfaction, organizational commitment (Tepper et al., 2004; Duffy et al., 2002; Tepper, 2000), self-efficacy (Duffy et al., 2002), procedural justice and organizational citizenship behavior (Tepper et al., 2004; Zellars et al. , 2002), contextual performance (Aryee et al., 2008) and self-confidence (Harvey et al., 2007); there are positive relationships between abusive supervision and workplace-family, family-workplace conflicts (Wu and Cao, 2015; Tepper, 2000), stress-related problems -depression- (Duffy et al., 2002; Tepper, 2000), work tension (Harvey et al., 2007), emotional exhaustion (Bolat et al., 2017; Grandey et al., 2007; Harvey et al., 2007; Tepper, 2000), active and passive non-productive job behaviors (Duffy et al., 2002), deviant behaviors (Ucok and Turgut, 2014), negative emotions (Zellars et al., 2002) and intention to quit (Pradhan and Jena, 2017; Harvey et al., 2007). Therefore, abusive supervision has important results on employees and organizations. The reduction in the sense of personal accomplishment is the dependent variable. Employee's personal sense of failure is an evaluation related to inadequate, powerless and incompetent to solve the problems encountered (Duru et al., 2014; Maslach et al., 2001). Individual negative evaluations may lead to a decrease on self-efficacy. Taylor (1991) also argued that interpersonal negative events may lead to affective, cognitive, and behavioral responses (cited in: Duffy et al., 2002). It is reasonable for an employee who is target of abusive supervision to respond affective, cognitive and behavioral reactions in this mechanism. Abusive supervision may affect employees' feelings of helplessness, lack of control and distress, especially in terms of affective reactions (Duffy et al., 2002). In this context, abusive supervision is considered as a source of interpersonal stress which may affect employees' professional life. Moreover, it is stated that abusive supervision 
means an interpersonal conflict and it is a chronic pressure on employees' feelings, self-efficacy and self-confidence (Harvey et al., 2007) and hence abusive supervision have a great impact on employees and this may lead to the loss of critical resources for employees (Pradhan and Jena, 2017). Therefore, abusive supervision may increase employees' feelings of personal failure through emotional exhaustion. The main purpose of this study is to investigate the mediating role of emotional exhaustion on the effect of abusive supervision on the decrease of personal sense of accomplishment.

The universe of the research consisted of teachers who work in schools in Giresun and Rize provinces. The sample was 169 teachers obtained by convenience sampling method. The questionnaire form was sent to the teachers' e-mails via a link prepared on the internet and the number of teachers who returned was 169. 169 sample of research composed of $74 \%$ women, $88 \%$ graduate and $12 \%$ post graduate, $75 \%$ married; and average age 33,40 and average working time 9,42 years.

Tepper (2000) developed a 15-item and one dimensional abusive supervision and this scale was adapted by Ulbegi et al. (2014) to Turkish.

Maslach and Jackson (1981) developed a 22-item and three dimensional burnout inventory and this scale was adapted by Ergin (1992) to Turkish. Emotional exhaustion and personal failure dimensions were used in this study. Abusive supervision had a positive effect on the decrease of personal sense of accomplishment. This result supported the results of various studies on this subject (Sezici and Yildiz, 2017; Aryee et al., 2008; Harvey et al., 2007; Tepper, 2000).

Abusive supervision had a positive effect on emotional exhaustion. This result supported the results of previous studies (Bolat et al., 2017; Grandey et al., 2007; Harvey et al., 2007; Tepper, 2000).

Emotional exhaustion had a positive effect on the decrease of personal sense of accomplishment. This result is consistent with the conclusion of Duru et al. (2014) on the negative relationship between emotional exhaustion and academic achievement.

According to the findings of mediation effect, emotional exhaustion had a full mediator role on the effect of abuse supervision on the decrease of personal sense of accomplishment. Emotional exhaustion affected personal failure much more. 


\section{Kaynakça / References}

Ashforth, B. (1994). Petty tyranny in organizations. Human Relations, 47(7), 755-778.

Ardıç, K. ve Polatcı, S. (2008). Tükenmişlik sendromu akademisyenler üzerinde bir uygulama:GOÜ örneği. Gazi Üniversitesi İktisadi ve İdari Bilimler Fakültesi Dergisi, 10(2), 69-96.

Aryee, S., Chen, Z.X.G.C. ve Debrah, Y.A. (2008). Abusive supervision and contextual performance: The mediating role of emotional exhaustion and the moderating role of work unit structure. Management and Organization Review, 4, 393-411.

Baron, R.M. ve Kenny, D.A. (1986). The moderator-mediator variable distinction in social psychological research: Conceptual, strategic, and statistical considerations. Journal of Personality and Social Psychology, 51(6), 1173-1182.

Bolat, O. İ., Bolat, T., Seymen, O. ve Yüksel, M. (2017). İstismarcı yönetim ve tükenmişlik: Lider-üye etkileşimi ve güç mesafesinin düzenleyici etkisi. Balıesir Üniversitesi Sosyal Bilimler Enstitüsü Dergisi, 20(38), 123-161.

Chin, W.W., Marcolin, B.L. ve Newsted, P.R. (2003). A partial least squares latent variable modeling approach for measuring interaction effects: results from a Monte Carlo simulation study and an electronic-mail emotion/adoption study. Information Systems Research, 14(2), 89-217.

Chin, W.W. (2001). PLS-graph user's guide version 3.0. Houston, Texas: C. T. Bauer College of Business, University of Houston.

Demir, N. (2010). Küçülmeye giden işletmelerde geri kalanların yaşadıkları tükenme sendromunun örgüte bağlllık üzerindeki etkisi. Öneri, 9(33), 185-198.

Duffy, M.K., Ganster, D.C. ve Pagon, M. (2002). Social undermining and social support in the workplace. Academy of Management Journal, $45,331-351$.

Duru, E., Duru, S., ve Balkıs, M. (2014). Tükenmişlik, akademik başarı ve öz düzenleme arasındaki ilişkilerin analizi. Kuram ve Uygulamada Ĕ̆itim Bilimleri, 14(4), 1263-1284. 
Ergin, C. (1992). Doktor ve hemşirelerde tükenmişlik ve maslach tükenmişlik ölçeğinin uyarlanması. (R. Bayraktar, ve İ. Dağ Ed.), 7. Ulusal Psikoloji Kongresi Bilimsel Çalışmaları içinde (s.143-154), Hacettepe Üniversitesi, Ankara.

Field, A.P. (2000). Discovering statistics using spss for windows. London: Sage Publications.

Fornell, C. ve Larcker, D.F. (1981). Evaluating structural equation models with unobservable variables and measurement error. Journal of Marketing Research, 18, 39-50.

Goldman, A. (2011). Demagogue to dialogue: An alternative to toxic leadership in corporate downsizings. Organizational Dynamics, 40, 235-241.

Grandey, A.A., Kern, J. ve Frone, M. (2007). Verbal abuse from outsiders versus insiders: Comparing frequency, impact on emotional exhaustion, and the role of emotional labor. Journal of Occupational Health Psychology, 12(1), 63-79.

Hair, J.F.Jr., Black, W.C., Babin, B.J., Anderson, R.E. ve Tatham, R.L. (2006). Multivariate data analysis. (6th Ed.), New Jersey: Pearson Prentice Hall.

Hair, J.F.Jr., Hult, T.M., Ringle, C.M. ve Sarstedt, M. (2013). A primer on partial least squares structural equation modeling (pls-sem). Thousand Oaks. CA: Sage.

Harris, K.J., Kacmar, K.M. ve Zivnuska, S. (2007). An investigation of abusive supervision as a predictor of performance and the meaning of work as a moderator of the relationship. Leadership Quarterly, 18(3), 252-263.

Harvey, P., Stoner, J., Hochwarter, W. ve Kacmar, C. (2007). Coping with abusive supervision: The neutralizing effects of ingratiation and positive affect on negative employee outcomes. The Leadership Quarterly, 18, 264-280.

Hobfoll, S.E. (1989). Conservation of resources: A new attempt at conceptualizing stress. American Psychologist, 44(3), 513-524.

Kellerman, B. (2004). Bad leadership: What it is, how it happens, why it matters. Boston, Massachusetts: Harvard Business School Press. 
Kelloway, E.K., Mullen, J. ve Francis, L. (2006). Divergent effects of transformational and passive leadership on employee safety. Journal of Occupational Health Psychology, 11(1), 76-86.

Lee, R.T. ve Ashforth, B. (1996). A meta-analytic examination of the correlates of the three dimensions of job burnout. Journal of Applied Psychology, 81, 123-133.

MacKinnon, D.P., Lockwood C.M. ve Williams, J. (2004). Confidence limits for the indirect effect: Distribution of the product and resampling methods. Multivariate Behavioral Research, 39(1), 99-128.

Maslach, C., Schaufeli, W.B. ve Leiter, M.P. (2001). Job burnout. Annual Review of Psychology, 52, 397-422.

Maslach, C. ve Jackson, S.E. (1981). The measurement of experienced burnout. Journal of Occupational Behavior, 2, 99-113.

Pradhan, S. ve Jena, L.K. (2018). Abusive supervision and job outcomes: A moderated mediation study. Evidence-based HRM: A Global Forum for Empirical Scholarship, 6(2), 137-152.

Sezici, E. ve Yıldız, B. (2017). Nevrotik kişilik özelliği ile kişisel başarı hissinde azalma ilişkisinde istismarcı yönetimin aracılık etkisi. Sosyal Bilimler Dergisi, 10(2), 50-76.

Sezici, E. ve Güven, Ö.Z. (2017). İstismarcı yönetici algısının kaytarma üzerindeki etkisinde duygusal tükenmenin aracılık rolü: Otel işletmelerinde bir inceleme. Anatolia: Turizm Araştırmaları Dergisi, 28(1), 58-68.

Shrout, P.E. ve Bolger, N. (2002). Mediation in experimental and nonexperimental studies: New procedures and recommendations. Psychological Methods, 7(4), 422-445.

Tepper, B.J. (2007). Abusive supervision in work organizations: Review synthesis, and research agenda. Journal of Management, 33, 261-289.

Tepper, B.J., Duffy, M.K., Hoobler, J. ve Ensley, M.D. (2004). Moderators of the relationships between coworkers 'organizational citizenship behavior and fellow employees' attitudes. Journal of Applied Psychology, 89(3), 455-465.

Tepper, B.J. (2000). Consequences of abusive supervision. Academy of Management Journal, 43(2), 178-190. 
Tierney, P. ve Tepper, B.J. (2007). Introduction to the Leadership Quarterly special issue: Destructive leadership. Leadership Quarterly, 18(3), 171-173.

Üçok, D. ve Turgut, T. (2014). İstismarcı yönetici davranışının işyerindeki sapkın davranışlar üzerindeki rolü. Eskişehir Osmangazi Üniversitesi İ̈BF Dergisi, 9(3), 163-179.

Ülbeği, İ.D., Özgen, H.M. ve Özgen, H. (2014). Türkiye'de istismarcı yönetim ölçeğinin uyarlaması: Güvenirlik ve geçerlik analizi. Çukurova Üniversitesi Sosyal Bilimler Enstitüsü Dergisi, 23(1), 1-12.

Ülkü, S. ve Bilgin, N. (1983). Stres:psikolojik zorlanma. Eğitim ve Bilim, 7(41), 20-28.

Wang, W., Mao, J., Wu, W. ve Liu, J. (2012). Abusive supervision and workplace deviance: The mediating role of interactional justice and the moderating role of power distance. Asia Pacific Journal of Human Resources, 50, 43-60.

Whitman, M.V., Halbesleben, J.R.B. ve Holmes, O. (2014). Abusive supervision and feedback avoidance: The mediating role of emotional exhaustion. Journal of Organizational Behavior, 35, 38-53.

Wu, S.Q. ve Cao, K. (2015). Abusive supervision and work-family conflict: The mediating role of emotional exhaustion. Journal of Human Resource and Sustainability Studies, 3, 171-178.

$\mathrm{Wu}$, T.Y. (2008). Abusive supervision and emotional exhaustion: The mediating effects of subordinate justice perception and emotional labor. Chinese Journal of Psychology, 50(2), 201-221.

Zellars, K.L., Tepper, B.J. ve Duffy, M.K. (2002). Abusive supervision and subordinates' organizational citizenship behavior. Journal of Applied Psychology, 87, 1068-1076.

\section{Kaynakça Bilgisi / Citation Information}

Acaray, A. (2019). İstismarcı yönetici algısının kişisel başarı hissinde azalma üzerine etkisinde duygusal tükenmenin aracı rolü.OPUSUluslararası Toplum Araştırmaları Dergisi, 12(18. UíK Özel Sayısı), 438-461. DOI: 10.26466/opus.584746 